\title{
CONHECENDO OS MODELOS DE CARREIRA DOS PROFISSIONAIS DA ÁREA DAS ARTES
}

\author{
Wesley Rodrigues da Costa* \\ Raquel Pereira Belo** \\ Anisia Sousa Pereira Neta*** \\ Flávio Henrique Mendonça do Nascimento***** \\ Josiane Alves Moraes ${ }^{* * * * *}$
}

RESUMO: A presente pesquisa foi realizada no âmbito da análise psicossocial do trabalho e das organizações e dessa forma buscou conhecer os modelos de carreira profissional dos profissionais da área das Artes. As transformações no desenvolvimento de carreiras acompanharam o desenvolvimento do trabalho e atualmente constituem-se modelos de carreira: carreiras sem fronteiras, carreira portfólio, âncoras de carreira, carreira protiana e craft careers. Fizeram parte da pesquisa 14 profissionais. $\mathrm{O}$ instrumento da pesquisa foi um roteiro de entrevista semiestruturada e questionário sociodemográfico. Os dados foram analisados por meio da Técnica da Análise de Conteúdo, proposta por Bardin (2011). Os resultados apontam que os modelos de carreira profissional elaborados por parte dos profissionais são a carreira de tipo empreendedor, âncoras de carreiras e craft careers e estes têm como órgãos empregadores as instituições públicas e privadas. Conclui-se que os entrevistados são profissionais motivados a exercerem suas profissões apesar das dificuldades encontradas para exercê-las, visto que alguns deles mantêm duas profissões, sendo a primeira aquela pela qual se optou cursar e, a segunda aquela pela qual tem identificação no campo das artes.

PALAVRAS-CHAVE: Modelos de carreira profissional; Trabalho na atualidade; Parnaíba-PI.

\footnotetext{
* Psicólogo pela Universidade Federal do Piauí, Brasil. E-mail: wesleyrodrigo.p@icloud.com.

** Doutora em Psicologia Social; Docente da Graduação e do Programa de Pós-Graduação em Psicologia na Universidade Federal do Piauí, Brasil.

**** Psicóloga pela Universidade Federal do Piauí, Brasil.

***** Psicólogo pela Universidade Federal do Piauí, Brasil.

******* Mestranda do Programa de Pós-Graduação em Psicologia da Universidade Federal do Piauí, Brasil.
} 


\section{CAREER MODELS OF ART PROFESSIONALS}

ABSTRACT: Current research was undertaken with the psychosocial analysis of labor and organizations and is an in-depth analysis of the professional career models of Art professionals. Transformations in the development of careers followed the development of labor and currently are career models: careers without borders, portfolio career, career anchors, protean career and craft careers. Fourteen professionals took part and a semi-structured interview and sociodemographic questionnaires were performed. Data were analyzed by the Bardin's Content Analysis Technique. Results show that professional careers models elaborated by professionals are entrepreneurship-type, career anchors and craft careers. Public and private institutions are the employing agents. Interviewees are motivated professionals who exercise their profession in spite of great difficulties. Many have two professions, the first is that which they opted to take and the other one is that which identifies them in the field of Arts.

KEY WORDS: Professional career models; Current work; Parnaíba PI Brazil.

\section{INTRODUÇÃO}

O grande marco no que concerne às novas formas de trabalho foi a Revolução Industrial (ORNELLAS; MONTEIRO, 2006). Ela apresentou uma nova forma de produzir, que, dentre algumas outras características, pode ser citado o trabalho coletivo: neste formato os trabalhadores perdem o controle sobre o processo de produção, e a força de trabalho passa a ser comprada e vendida (MATOS; PIRES, 2006).

Para Balassiano, Ventura e Fontes Filho (2004), as mudanças nas organizações têm sido transformadoras das práticas administrativas. A ideia de carreira também sofre modificações, deixando de ser voltada para a organização, para na contemporaneidade, ser de responsabilidade da pessoa. Balassiano e Costa (2013) defendem ainda o quanto as carreiras tendem a ser associadas ao percurso profissional de cada sujeito de forma independente da área de formação ou da empresa onde essa trajetória se desenvolve. As ênfases, na atualidade, são dadas às carreiras liberais e ao mercado informal, sendo perceptível no campo do trabalho 
brasileiro uma grande quantidade de trabalhadores atuando dentro da perspectiva do trabalho informal.

Corroborando com o que já foi dito, Wilkoszynski e Vieira (2013) pontuam um reposicionamento que os sujeitos assumem em relação às suas carreiras deixando de ter uma postura passiva para uma postura ativa, no qual os mesmos assumem a responsabilidade de se incluir e se manter estáveis visando sua sustentabilidade no mundo do trabalho. A fim de entender tal processo de transformação - sobre o conceito de carreira profissional e como ela é vista atualmente - torna-se importante pontuar algumas definições a respeito o tema. Para Chanlat (1995), foi no século XIX que surgiu a noção de carreira. O autor apresenta a definição da palavra "carreira" a partir da acepção de um ofício que apresenta progressão.

Bendassolli (2009a) aponta para uma ambiguidade com relação ao conceito de carreira ligada ao fato de colecionar ampla diversidade de definições. Alguns exemplos acerca do significado podem ser citados quais sejam: a atividade laboral remunerada ou não; manifestação da mais pura idiossincrasia de um artista; a ocupação profissional; vocação; pertencimento a um grupo profissional ou trajetória de uma pessoa que trabalha por conta própria. Para Dutra (2010), a carreira pode ser pensada partindo do pressuposto de várias fases e mudanças que irão variar em função das pressões originadas tanto por parte do trabalhador como do ambiente onde está inserido, neste sentido a carreira caracteriza-se como fruto da ligação entre o trabalhador e a empresa, compreendendo as perspectivas de ambas.

\subsection{CONTEXTUALIZANDO A CARREIRA PROFISSIONAL}

Chanlat (1995) apresenta quatro tipos de carreiras que se reportam aos aspectos profissionais sendo elas: burocrática, profissional, empreendedora e sociopolítica. Assim, de acordo com tal perspectiva, pelas contribuições de diversos autores, a carreira é vista de um modo tradicional e tem como características a estabilidade e o crescimento dentro da organização.

A carreira do tipo burocrática se caracteriza por manter uma estrutura hierarquizada regulamentada dentro da organização, com vistas à impessoalidade e centralização do poder (CHANLAT, 1995). Já a carreira do tipo profissional tem por 
característica a motivação para o domínio do conhecimento e da qualificação, fator que contribui para o desenvolvimento profissional associado à reputação e ao saber decorrente do crescimento interno na sua organização, proporcionando vantagens para o desenvolvimento da carreira tanto dentro de uma organização como em diferentes organizações ou como carreiras paralelas (TOLFO, 2002).

A carreira intitulada empreendedora baseia-se no pressuposto da possibilidade individual a qual se fundamenta no talento e no trabalho. Neste sentido existe uma expectativa para criatividade, inovação e autonomia. É importante mencionar que esta conceituação que embasa a carreira empreendedora pode ser problemática, uma vez que nem todos os indivíduos possuem competências como o empreendedorismo ou adaptação para a alta competitividade do mercado (TOLFO, 2002).

Por fim, a carreira do tipo sociopolítico está ligada às habilidades sociais e ao poder de relações que um sujeito pode ter, assim, Chanlat (1995) aponta como elemento central a riqueza de conhecimento de relações e de ser de um nível social bem estruturado; ainda segundo o autor são exemplos em que podem ser encontradas nesse tipo de carreira as empresas familiares, comunitárias ou clãs. $\mathrm{O}$ tópico seguinte explana sobre os modelos de carreira na perspectiva organizacional tendo em vista os profissionais que dentro de uma organização ou de forma autônoma fazem seu próprio caminho.

Os modelos de carreira na perspectiva organizacional dividem-se em carreiras sem fronteiras, carreira portfólio, âncoras de carreira, carreira protiana e craft careers. Oliveira et al., (2010) pontuam que a carreira sem-fronteiras tem como característica os diferentes graus de movimentações físicas e psicológicas que uma pessoa encara em sucessivas situações de emprego. Assim, a carreira sem fronteiras corresponde a um tipo de carreira que toma seu lugar em uma diversidade de contextos, na medida em que a pessoa não fica confinada a um único emprego e atravessa fronteiras e suas barreiras correspondentes (BENDASSOLLI, 2009a). Tendo em vista que nesse modelo de carreira o sujeito, através de sua subjetividade, imprime significado ao seu trabalho, na sua carreira a realização da atividade tornase cada vez mais permeável.

Em concordância com as ideias sobre as novas formas de se pensar o 
trabalho, as vias de emprego e carreira, é que se elabora uma ação caracterizada como o modelo de carreira portfólio: aqui a carreira é definida pela diversidade de atividades que compõem todo o escopo profissional, a partir do qual o indivíduo tem competência para atuar. Outra característica deste tipo de carreira é a fragmentação de atividades laborais (BENDASSOLLI, 2009b).

Assim, diante da fragmentação do trabalho e, consequentemente, das organizações, segundo Bendassolli (2009a), tem-se as carreiras fragmentadas, quando as formas de trabalhos são exercidas em uma estrutura temporária nas organizações, ou através de "bicos", prestação de pequenos serviços para conhecidos e exercício de mais de uma atividade por meio de dois ou mais empregos.

Carreira Proteana trata-se, sobretudo, de um reflexo dos novos arranjos de carreira, sendo um produto do atual cenário do mercado de trabalho, que por sua vez demanda uma nova lógica no relacionamento da díade empresa/empregados, afetando também a gestão do desenvolvimento dos profissionais. Esta lógica que permeia o relacionamento entre empresa e empregados, implica em uma gestão humanizada e flexibilizada por parte da organização, contemplando a subjetividade de cada trabalhador; para os profissionais, estes devem estar em contínua formação profissional e serem adaptados às mudanças advindas por fatores pessoais ou ambientais (NEVES; TREVISAN; JOÃO, 2013).

Por fim, no modelo de carreira craftcareers, o sujeito exerce o gerenciamento e a construção de sua própria carreira. A exemplo disto, Bendassolli (2009a) cita o paradigma do artesão no período que compreende ao pré-capitalismo, sendo este um sujeito capaz de se expressar por meio da criação e da execução do seu trabalho, construindo seu lugar no mundo por meio da sua obra, o que vem a construir também sua identidade. $\mathrm{O}$ autor traz essa visão de carreira para a modernidade, $\mathrm{e}$ pontua " $[. .$.$] o ideal do artesão é recarregado com características como criatividade,$ energia, autonomia e domínio de competências". Assim, continua o autor, o sujeito estaria envolvido de forma intensa e autônoma na construção de carreira como um processo artesanal. Nem sempre o planejamento de carreira é realizado, sendo o emprego visto na maioria dos casos como uma oportunidade conquistada na sorte. Acerca disso torna-se relevante explanar sobre o planejamento de carreira.

Estudos sobre carreiras relatam que por muito tempo atribuiu-se às 
organizações de trabalho o encargo pela carreira de seus profissionais. Contudo, na virada para o século XXI muitas modificações ocorreram, tanto no contexto socioeconômico que estabelece e destaca um ambiente de negócios dinâmico e competitivo nas instituições, como nos espaços de trabalho que se tornam mais exigentes, transferindo ao indivíduo a responsabilidade pelo domínio, direcionamento e construção de seu percurso profissional (DE LUCA; ROCHA-DEOLIVEIRA; CHIESA, 2016).

No que concerne ao planejamento de carreira, segundo as considerações de DUTRA (2010), dois fatos devem ser considerados quando se pensa na natural resistência que o ser humano tem no que tange ao planejamento de suas carreiras: 1) que a trilha profissional é vista como algo dado e 2) que as pessoas não recebem qualquer estímulo ao longo da vida.

Neste sentido, ainda segundo o autor, percebe-se na grande maioria da população um olhar para a carreira com vistas ao surgimento de oportunidades e a busca do aproveitamento das mesmas, deixando de atuar de forma ativa sobre a carreira e permitindo se inserir em uma realidade apresentada pelo ambiente. $\mathrm{O}$ sujeito diante das condições oferecidas pelo ambiente e na busca a uma adequação às suas preferências e características pessoais deve ter uma reflexão sobre as oportunidades de carreira que o ambiente oferece e, atrelado a isto, buscar de forma subjetiva pensar sobre o que gosta de fazer e de que forma a execução do trabalho pode satisfazê-lo ou estimulá-lo. Nesse sentido, Pedrosa e Santos (2015) corroboram que com a valorização das pessoas e do conhecimento, o conceito mecanicista de carreira mudou, dando ênfase ao indivíduo e às suas relações com a família e trabalho. Entretanto, ressalta-se que as transições pelas quais passam os modelos de carreira, resultam muitas vezes em tensões relacionadas a interesses que podem entrar em conflito como as necessidades do trabalhador envolvido, além da gestão de um equilíbrio profissional, pessoal e familiar (MONTEIRO; LEITE, 2019).

Diante disto, Dutra (2010) propõe um modelo de orientação de carreira, que tem por objetivo: 1) proporcionar que as pessoas pensem de forma crítica a respeito das suas carreiras; 2) propiciar condições para que as pessoas planejem suas carreiras; 3) propiciar a reflexão das pessoas sobre a realidade pessoal e profissional; 4) fornecer suporte ao desenvolvimento dos objetivos de carreira, além 
de monitoramento da carreira em perspectiva longitudinal.

London e Stumph (apud DUTRA, 2010) propõem um modelo no ano de 1982, que pontua três tarefas dependentes da pessoa para a realização do planejamento de suas carreiras. Tais tarefas (delineamento dos objetivos de carreira - aspectos de suas qualidades pessoais; autoavaliação - avaliação das oportunidades que a empresa oferece e capacitação - aquisição de experiências profissionais) dizem respeito a um processo de avaliação por parte do indivíduo de suas qualidades, interesses e potenciais. Diante disso, os profissionais precisam delinear suas aptidões, ter nítidos e definidos os seus objetivos de carreira e qual o procedimento necessário para alcançar os resultados que almejam (MONTEIRO; LEITE, 2019).

Tendo em vista tudo que já fora exposto e considerando a importância de se conhecer os modelos de carreiras dos profissionais artistas, faz-se necessário explanar a respeito de alguns apontamentos sobre o campo das artes.

\subsection{CONTEXTUALIZANDO O CAMPO DAS ARTES}

Desde os primórdios da humanidade, os seres humanos buscam formas de se expressar artisticamente seja por meio da dança, teatro, pintura e música (GOMBRICH, 2000). Uma indagação é apresentada na introdução do livro "Iniciação a História da Arte" com autoria de Janson e Janson (1996), qual seja "por que o homem cria?". A pergunta que busca saber o motivo ao qual o homem cria é explicada segundo a proposição de que existe um impulso de reconstrução ao seu $e u$ e ao meio ambiente de uma forma ideal. Ainda segundo os autores é através da arte que as pessoas podem revelar a visão que têm das coisas por meio de procedimentos que não podem ser expressos de outra forma.

As expressões artísticas, neste sentido, movimentam a venda de produtos diversificados em um mercado nacional, regional e local. A arte no Piauí é representada por meio de diversos segmentos por meio das manifestações artísticas e culturais, expressas na poesia e literatura, teatro, música, artes visuais, cinema, folclore piauiense a qual proporciona campo de trabalho aos artesãos que se utilizam das mais diversificadas matérias-primas para a realização de seu trabalho como, por 
exemplo, a madeira para esculpir santos, sendo esta técnica conhecida como arte santeira (DIAS, 2013).

Outro exemplo é o artesanato parnaibano, que segundo Menezes (2013) é representado pelas diversas associações de artesanato responsáveis pela produção dos mais variados produtos como, por exemplo, tapetes de taboa, peças confeccionadas em argila, palha a partir da carnaúba, tecidos rendados. O artesanato é considerado uma rica forma de expressão de um povo, representando muitas vezes a história da comunidade. Nesse contexto expressivo tem-se notado de forma considerável o poder de geração de renda e o impacto das práticas artesanais na questão da inclusão social e na potencialização de vocações regionais (BRASIL, 2012).

Sobre o artesanato no Piauí, mais especificamente no que concerne à História da Organização Artesanal no Estado, considera-se importante esclarecer que este surgiu município de Parnaíba, pois no ano de 1968, por meio do Serviço Social do Município (SERSOM), foi instituída a Cooperativa Artesanal Mista de Parnaíba, orientando e estimulando os artesãos a confeccionarem seus produtos no sentido de elevar a comercialização e aumentar a renda financeira (SILVA FILHO, 1987).

Dias (2013) aponta que o artesanato piauiense é uma referência nacional pela sua diversidade de produtos, aos quais podem ser citados, por exemplo: bordados, rendas de bilros, cestaria de palhas, trançados de fios, cerâmicas e a arte santeira, dentre outros. Configura-se como uma atividade de cunho tradicional e centenária, oriunda dos tempos colônia, que por sinal foi neste período que tais práticas artesanais se configuraram como uma das mais importantes profissões dos sertões piauienses.

Entende-se por arte popular "o conjunto de atividades poéticas, musicais, plásticas, dentre outras expressivas que configuram o modo de ser e viver do povo de um lugar", havendo diferenças entre a arte popular e o artesanato: no primeiro caso, a originalidade se configura como de suma importância, sendo importante que este domine a matéria-prima; no caso do artesão, por outro lado, escolhe-se um modelo e o reproduz tal qual o original, afirmando sua capacidade de expressão. Características do artista popular dizem respeito ao pertencimento deste ao povo bem como à contribuição das suas obras no sentido de disseminar a identidade cultural da região traduzindo o belo e apresentando elementos estéticos (BRASIL, 2012). 
A canção configura-se como uma expressão artística com elevado poder de comunicação, quando difundida pelos meios urbanos e alcançando ampla dimensão da realidade social (MORAES, 2000). Os seres humanos estão acostumados aos sons e ruídos do ambiente onde estão inseridos, que na maioria das vezes não tomam consciência deles. Neste sentido é que se torna válido acrescentar que os sons que são apresentados diariamente às pessoas permitem que estas realizem suas atividades diárias sem a exigência de atenção centrada de quem ouve.

Sobre teatro no contexto do mundo ocidental, este tem suas origens no século VI a.C. na Grécia antiga, em seu processo histórico sofreu muitas transformações, as quais refletiram em sua forma de comunicação e expressão, porém mantendo em sua essência o caráter de ser uma arte social, por contemplar o encontro entre pessoas, o coletivo (ROCHA et al., 2016).

Um conceito importante sobre teatro trata-se da teatralidade, que além de arte é também uma característica que diz respeito à perceptibilidade e expressividade humana, assim tal conceito acaba por significar uma força potencial, a qual é vital para as mais variadas formas com que o homem interage com o mundo. Outra característica da teatralidade seria que esta acontece em função do olhar de quem a testemunha (OLIVEIRA, 2017).

Neste sentido, existe ainda uma condição para a teatralidade, que consiste na identificação, a que é produzida pelo outro, e também pelo processo de criação, no qual há a projeção dessa criação pelo sujeito sobre seu entorno, assim tanto a identificação como a criação ocorrem em outros espaços, os quais são diferentes do cotidiano, passando a existir pelo olhar de um expectador (FÉRAL, 2015).

O texto de Lívia Ribeiro Lima (2010), publicado pelo Centro Nacional de Folclore e Cultura Popular, versa sobre uma das expressões artísticas de grande relevância no Piauíe em Parnaíba. Segundo a autora, o Estado do Piauíé nacionalmente conhecido pelos trabalhos desenvolvidos com arte santeira, que se caracteriza por apresentar os santos em forma de escultura. Há em média 50 escultores em madeiras no Estado do Piauí, distribuídos pelos municípios de Teresina, Parnaíba, José de Freitas, Pedro II e Campo Maior. O precursor dos trabalhos em arte santeira foi José Alves de Oliveira, conhecido como mestre Dezinho. Em Parnaíba, tem-se o nome de Francisco Ribeiro como influência aos vários escultores na cidade: sua produção 
apresenta trabalhos de esculturas representando a figura de cachorros com galhos de pau.

Assim, observam-se, como já fora exposto, os diversos modelos de carreiras que representam os profissionais ligados ao campo como, por exemplo, a empreendedora e a craft careers. As possibilidades de atuação no mercado de trabalho com artes são diversas: as pessoas executam seus trabalhos de acordo com suas habilidades e interesses pessoais criando produtos diferentes confeccionados com as mais diversas matérias-primas (BENDASSOLLI, 2009a).

Diante do exposto e considerando a relevância de se conhecer sobre os modelos de carreira profissional dos profissionais da área das artes na atualidade em Parnaíba, propõe-se a presente pesquisa.

\section{OBJETIVOS}

Conhecer os modelos de carreira profissional vivenciados e/ou planejados por profissionais de artes da cidade de Parnaíba-PI.

\section{MÉTODO}

\subsection{PARTICIPANTES}

O estudo contou com a participação de 14 entrevistados, em sua maioria homens (8) e mulheres (6). Quanto aos critérios de inclusão, os participantes deveriam ser maiores de 18 anos, trabalhar como artista - considerando a arte como uma profissão e obtenção de renda, seja exercendo o trabalho formal ou informal.

\subsection{INSTRUMENTO}

Foi utilizado um questionário sociodemográfico para identificação do perfil dos entrevistados, um roteiro de entrevista semiestruturada para conhecer os modelos de carreira profissional dos participantes, observando, ainda, os objetivos elaborados para o desenvolvimento da carreira, enquanto profissionais das artes. 


\subsection{PROCEDIMENTO}

As entrevistas foram realizadas em lugares públicos da cidade e/ou nos locais de trabalhos dos referidos profissionais. Independentemente da situação, durante a abordagem, foi perguntado a cada pessoa se poderia participar de uma pesquisa realizada pelo curso de graduação de Psicologia da Universidade Federal do Piauí, e, caso aceitasse, o respondente teria acesso a um Termo de Consentimento Livre e Esclarecido, que ele assinava demonstrando estar de acordo. O estudo seguiu as normas e procedimentos éticos conforme a resolução 466/12 do Conselho Nacional de Saúde (CAAE: 45381215.0.0000.5214; Instituição Proponente: Universidade Federal do Piauí - UFPI) que estabelece as diretrizes e normas regulamentadoras de pesquisas envolvendo seres humanos.

\subsection{ANÁLISE DOS DADOS}

Os dados foram analisados de acordo com a proposta de Bardin (2011), que aponta algumas etapas da análise - pré-análise, que consiste no primeiro contato com o material a ser estudado, desenvolvimento de hipóteses e dos objetivos da pesquisa; codificação, quando se realiza a escolha de unidades de registro e de contexto; categorização, na qual se classificam elementos que compõem um conjunto que são reagrupados por possuírem características comuns o que, consequentemente, favorece a realização da etapa da inferência. Estas foram as etapas adotadas para a análise dos dados obtidos por meio das entrevistas.

\section{RESULTADOS E DISCUSSÃO}

Os 14 participantes da pesquisa apresentam o seguinte perfil sociodemográfico: a maioria solteiros (8), com idades variando entre 22 e 61 anos; do total de respondentes, 11 indivíduos disseram ser natural de Parnaíba; o grau de educação escolar variou entre fundamental incompleto e pós-graduação; o tempo médio de atuação na profissão variou de quatro a 40 anos; quanto aos profissionais 
vinculados à alguma organização, estes prestam serviços às mesmas em uma média de tempo que vai de um a 20 anos.

As questões que nortearam o curso da presente pesquisa possibilitaram conhecer os diversos aspectos traçados nos objetivos específicos acerca dos profissionais da área das artes da cidade de Parnaíba-PI. Os resultados obtidos por meio das questões da entrevista possibilitaram agrupar e categorizar as respostas, conforme apresentado no Quadro 1:

Quadro 1. Eixos temáticos: modelos de carreira entre os profissionais das artes

\begin{tabular}{|c|c|c|}
\hline \multicolumn{3}{|c|}{ (Continua) } \\
\hline Questão norteadora & Categorias & $\mathbf{F}$ \\
\hline \multirow{3}{*}{$\begin{array}{l}\text { Como ocorreu seu } \\
\text { processo de escolha } \\
\text { profissional? }\end{array}$} & 1.1. Identificação, dom/vocação, gostar do que faz & 8 \\
\hline & 1.1.1. Identificação desde a infância & 4 \\
\hline & 1.2. Influência familiar & 5 \\
\hline \multirow{2}{*}{$\begin{array}{l}\text { Fale a respeito de sua } \\
\text { inserção no mercado } \\
\text { de trabalho }\end{array}$} & 1.1. Convite & 4 \\
\hline & 1.2. Geração de renda & 3 \\
\hline \multirow{3}{*}{$\begin{array}{l}\text { Em sua prática } \\
\text { profissional você se } \\
\text { identifica com a sua } \\
\text { área de atuação? }\end{array}$} & 1.1. Sim (demais, claro, total) & 18 \\
\hline & 1.1.1. Gosta do que faz/identificação/realização & 11 \\
\hline & 1.1.2. Vivência e compartilhamento da arte & 5 \\
\hline \multirow{7}{*}{$\begin{array}{l}\text { Existem fatores } \\
\text { motivadores para que } \\
\text { você permaneça na } \\
\text { carreira? Quais seriam } \\
\text { eles? }\end{array}$} & Fatores motivadores para permanência na carreira & \\
\hline & 1. Sim & 11 \\
\hline & $\begin{array}{l}\text { 1.1. Gosta do que faz, satisfação, vocação (amor à dança, ao teatro, à profis- } \\
\text { são, à arte) }\end{array}$ & 12 \\
\hline & 1.2. Renda & 5 \\
\hline & $\begin{array}{l}\text { 1.3. Levar a emoção e reflexão (mostrar o lado poético das coisas, expressão } \\
\text { por meio das telas e cores) }\end{array}$ & 4 \\
\hline & Fatores desmotivadores para permanência na carreira & \\
\hline & 2. Sim & 6 \\
\hline
\end{tabular}


(Conclusão)

\begin{tabular}{|c|c|c|}
\hline Questão norteadora & Categorias & $\mathbf{F}$ \\
\hline \multirow{5}{*}{$\begin{array}{l}\text { O que você entende } \\
\text { por plano de carreira } \\
\text { profissional? }\end{array}$} & 1. Compreensão & \\
\hline & 1.2. Aprimoramento contínuo, acúmulo de experiências & 10 \\
\hline & 1.3. Planejamento de organização das atividades (plano de metas) & 5 \\
\hline & 2. Objetivos & \\
\hline & 1. Formação profissional: superior, especialização, cursos & 4 \\
\hline $\begin{array}{l}\text { Como você } \\
\text { administra sua } \\
\text { carreira profissional } \\
\text { frente às mudanças } \\
\text { no mercado de } \\
\text { trabalho? }\end{array}$ & $\begin{array}{l}\text { 1. Acompanhar as mudanças do mercado: desenvolvimento tecnológico, as } \\
\text { novas linguagens artísticas, inovação, cursos, viagens }\end{array}$ & 15 \\
\hline \multirow{4}{*}{$\begin{array}{l}\text { Você acredita que tem } \\
\text { acompanhado tais } \\
\text { mudanças enquanto } \\
\text { profissional? }\end{array}$} & 1.1. Sim & 11 \\
\hline & 1.1. Atualização dos conhecimentos, aprimoramento & 7 \\
\hline & 1.1.1. Outros profissionais, tecnologia, tecnologias sociais & 4 \\
\hline & 1.2. Não & 2 \\
\hline \multirow{3}{*}{$\begin{array}{l}\text { Você acredita na sua } \\
\text { carreira como um } \\
\text { projeto individual } \\
\text { ou sendo um projeto } \\
\text { estruturado pela } \\
\text { organização? }\end{array}$} & 1.1. Ambos: pessoal e organizacional & 5 \\
\hline & 1.1.1. Agregar valores à empresa & 5 \\
\hline & 1.2. Projeto individual, autônomo & 5 \\
\hline \multirow{2}{*}{$\begin{array}{l}\text { Como você se sente } \\
\text { estando vinculado a } \\
\text { uma instituição? }\end{array}$} & $\begin{array}{l}\text { 1. Se sentir bem (organização familiar, autonomia, valorização, boa remunera- } \\
\text { ção, transformação pessoal) }\end{array}$ & 13 \\
\hline & 1.2. Pertencimento grupal & 5 \\
\hline \multirow{2}{*}{$\begin{array}{l}\text { Como você se sente } \\
\text { sendo profissional } \\
\text { autônomo? }\end{array}$} & 1. Maravilhoso/realizado/pleno, bem & 7 \\
\hline & 1.1. Autonomia: horário para criação (viver todas as horas do dia) & 12 \\
\hline \multirow{2}{*}{$\begin{array}{l}\text { Quais as possibilida- } \\
\text { des de emprego na } \\
\text { sua área na cidade de } \\
\text { Parnaíba? }\end{array}$} & $\begin{array}{l}\text { 1. Poucas (não se dá para viver de arte): áreas públicas, mercado por tempo- } \\
\text { rada, fraco }\end{array}$ & 7 \\
\hline & $\begin{array}{l}\text { 1.2. Oportunidade: secretarias de cultura, turismo, artesanato, dança na esco- } \\
\text { la, peças de teatro, eventos, recreador, facilitador de cultura e arte, educador } \\
\text { físico, educação especial, projeto MAIS EDUCAÇÃO, universidades, música }\end{array}$ & 18 \\
\hline
\end{tabular}

Fonte: Dados da Pesquisa 
Segundo os profissionais entrevistados as possibilidades de emprego na cidade são em diversos órgãos empregadores como escolas de música, balé, órgãos públicos e casas de shows. Apesar disto, tais profissionais consideram poucas as possibilidades de empregos na cidade, como pode ser observado em um dos discursos elaborado: "Mínimos. Porque geralmente a música era pra estar vinculada ao currículo normal da escola. Grade curricular é lei, e quando respeitam, limitam o profissional" - (Participante 1).

Observou-se que os artistas, tanto os autônomos quanto os vinculados à alguma organização, sentem-se bem em trabalhar com artes, fato este que pode ser notado pela formação inicial dos mesmos que em sua maioria é de nível superior ou técnica em outras áreas que não a das artes: há profissionais, por exemplo, que são graduados em pedagogia, ciências contábeis, sistemas de informação e trabalham na área de formação. Muitos deles exercem suas profissões de formação para ajudar a manter o trabalho como artista, por considerarem que viver exercendo apenas a profissão no campo das artes não é possível em relação ao aspecto financeiro. Neste sentido há uma satisfação considerada como fundamental para o exercício de suas profissões, como pode ser observado sobre o sentimento em ser profissional autônomo: "Ótimo, realizado, pleno totalmente. Eu vivo todas as horas do dia, não somente depois das 18hrs" - (Participante 2).

Pode-se observar que os artistas citados conduzem suas vidas profissionais de acordo com as novas formas de gestão de carreira, pautada na ideia de que o funcionário, ao contrário do passado, não está estagnado na organização, mas em constante movimento. Neste sentido, os resultados apontam para um planejamento da carreira de forma individual e organizacional, no qual ambos têm papel relevante no desenvolvimento das mesmas, que de acordo com Balassiano e Costa (2013) esta, na modernidade, transcende a própria existência de uma organização, sendo dado ênfase às carreiras liberais bem como às relacionadas ao mercado informal.

Os autores ainda pontuam que um considerável número de trabalhadores desenvolve suas carreiras exercendo alguma função da cadeia produtiva do setor informal. Nesta perspectiva, a ideia da carreira como um projeto individual ou estruturado pela organização faz-se presente nas realidades dos entrevistados, visto que alguns profissionais ainda têm a visão de carreira como vinculado a uma 
organização: "Estruturado pela organização. O profissional precisa de apoio, pois sozinho não consegue nada" - (Participante 3); outros, em uma visão contrária, concebem a carreira como estruturada individualmente "Totalmente individual. Se não for eu, eu tô ferrado" - (Participante 4).

Quanto aos modelos de carreira dos profissionais, pôde-se observar coerência com o que é proposto por Chanlat (1995), que caracteriza a carreira de tipo empreendedor como aquela com ligação de uma pessoa às atividades em uma empresa independente, constituindo-se como um tipo de carreira identificada com o empreendedor econômico. O autor aponta como exemplo de profissionais que seguem este modelo de carreira, os artistas, os fundadores de empresas culturais e comunitárias e os artesãos.

Também podem ser ressaltadas as características nos discursos dos respondentes que dão indícios do modelo de carreira intitulado âncoras de carreiras, justamente por considerar que este modelo leva em consideração uma gama de talentos, motivos e valores que o indivíduo tem consciência da existência e da relevância para a carreira. Trevisan et al., (2016) afirmam que ao passo em que as pessoas se percebem e agregam conhecimento quanto às suas preferências profissionais, podem escolher de forma mais consciente o direcionamento de sua carreira. De acordo com Schein (1990), todos trabalhadores desenvolvem uma âncora de carreira, entretanto, é possível notar insuficiente flexibilidade na situação de trabalho de muitas ocupações profissionais que limitam a expressividade deste modelo de carreira; nesse sentido as âncoras podem se mostrar mais prontamente em bobbies.

Diante deste acúmulo de experiências profissionais, o indivíduo cristaliza uma imagem profissional na qual se reconhece e se faz conhecer. Este acúmulo de experiências profissionais recebe o nome de âncora de carreira, com tais experiências divididas em oito dimensões: empreendedorismo, estilo de vida, desafio puro (no qual o indivíduo dá importância à possibilidade de inovação), serviço e dedicação, gestão de pessoas, autonomia (prevalência da liberdade de escolha bem como a ausência de chefes diretos), segurança no emprego e competência técnico-profissional. No presente estudo, cabe enfatizar que o estilo de vida dos profissionais da arte em Parnaíba-PI demonstrou indícios de autoexpressão; desafio 
puro e autonomia (BENDASSOLLI, 2009a).

Um outro modelo de carreira que pôde ser observado entre os profissionais que participaram do estudo foi a craft careers, visto que os entrevistados indicaram poder exercitar o seu poder de agente construtor de sua própria carreira, tendo como paradigma subjacente o trabalho do artesão, que na noção moderna de carreira tem o ideal recarregado com características como criatividade, energia, autonomia, domínio de competências. Desta forma, a construção de carreira vista como um processo artesanal sugere intensa implicação do indivíduo em uma ampla margem de autonomia de sua parte (BENDASSOLLI, 2009a).

Os resultados aqui apresentados corroboram com achados de pesquisas atuais, a exemplo de Vieira e Sousa (2019), que buscaram analisar a carreira de artesãos de arte em madeira e apresentaram como aporte teórico o modelo de craft careers, apresentaram características condizentes com o perfil dos profissionais criatividade e a independência em relação a conceber suas obras.

Diante dos modelos de carreira identificados entre os artistas da cidade de Parnaíba e apresentados acima, torna-se importante discutir os objetivos traçados para o desenvolvimento da carreira por parte destes profissionais. Primeiramente, dois pontos merecem ser observados: a compreensão dos respondentes acerca do que se trata o planejamento da carreira profissional, e, diante disso, quais são os objetivos traçados. As respostas que apresentam à ideia de acúmulo de experiências e aprimoramento contínuo demonstraram considerável relevância, assim como a noção de planejamento e organização das atividades. Neste sentido, as respostas vão de encontro à própria noção de carreira como a sequência de posições ocupadas e de trabalhos que a pessoa executa ao longo de sua vida, envolvendo uma série de estágios pelos quais passa e a ocorrência de transições que de um lado refletem necessidades, motivos e aspirações individuais e de outro, expectativas e imposições da organização e da sociedade (LONDOM; STUMPH, 1982 apud DUTRA, 2010.)

Ao que concerne os objetivos, pode-se observar que as respostas evocaram a ideia de formação profissional como um aspecto essencial. Desta maneira, a educação acadêmica tem fundamental papel, segundo os respondentes, para as suas carreiras. Pontua-se aqui também a importância dada para a legalização do negócio, visto que a maioria dos entrevistados autônomos ainda não tem Cadastro Nacional 
de Pessoa Jurídica, nem é Microempreendedor Individual - MEI. Outro objetivo ressaltado foi a ideia de disseminação da arte para fora da cidade, alcançando assim o âmbito nacional.

Dessa forma cita-se Munhoz e Melo-Silva (2011) quando pontuam que na contemporaneidade, o contexto de trabalho exige, com mais veemência, que os trabalhadores detenham cada vez mais um conjunto de competências, envolvendo conhecimentos, habilidades e atitudes para lidar com a carreira de forma eficaz. Diante das exigências impostas pelo mercado de trabalho, torna-se necessário que o trabalhador se sinta motivado a estar buscando aprimoramento para manejar da melhor forma seu dia a dia profissional.

Nesse sentido, buscou-se investigar também a existência de fatores motivadores para a permanência na carreira e por meio das respostas foi possível perceber o envolvimento que os trabalhadores têm com suas profissões sentindose satisfeitos plenamente: "Existe. Amor à profissão, amor à arte, 100\% amor à arte que você faz"- (Participante 5). A motivação no trabalho tem sido um construto no qual várias teorias já foram elaboradas. Inicialmente as tentativas de explicação eram relativamente simples, baseadas em geral em uma única dimensão e não levavam em consideração a dinâmica entre o indivíduo e seu trabalho: exemplo disso é o proposto na teoria da administração científica de Taylor, que considerava o salário como motivador fundamental. Entretanto, ao longo dos anos, muitas outras foram sendo elaboradas, sendo caracterizadas por sua maior complexidade e por sua abordagem envolvendo a tríade psicossociocultural (TAMAYO; PASCHOAL, 2003).

No bojo das teorias motivacionais cabe citar a Teoria da Hierarquia de Necessidades, que tem Maslow (1954) como autor. Nesta perspectiva ele identificou as principais necessidades do ser humano e as classificou em uma escala ascendente de hierarquização didaticamente demonstrada em uma pirâmide. Compreende estas escalas, uma sequência que vai da base ao topo da pirâmide: as necessidades fisiológicas, necessidades de segurança, necessidades sociais, necessidades de estima e necessidades de autorrealização. Constitui-se um aspecto dessa teoria a premissa de que cada tipo de necessidade deve ser satisfeita suficientemente antes do que os outros colocados nos níveis mais altos na escala proposta (PÉREZ-RAMOS, 1990). Desta forma, ao passo que uma necessidade de nível mais básico é satisfeita, 
outra de nível mais elevado surge como preponderante, passando a motivar mais intensamente o comportamento do indivíduo. Este modelo constitui-se de forma bastante flexível, de forma que o próprio criador da teoria reconhece a existência de variações individuais, especialmente no que diz respeito à intensidade das necessidades e ao momento em que se manifestam como prevalecentes. Maslow admite, inclusive, a possibilidade de haver prevalência das necessidades de nível mais elevado na escala, por exemplo, as psicológicas, sem que as de categorias inferiores tenham sido plenamente satisfeitas. Assim, observa-se na presente pesquisa que os fatores motivadores para permanecer na carreira ocupam lugar fundamental na vida dos indivíduos (PÉREZ-RAMOS, 1990).

$\mathrm{O}$ amor à profissão de artista foi citado pelos entrevistados como um fator motivador para que os profissionais continuem trabalhando na área: alguns declararam que gostam do trabalho que exercem, embora na visão destes, constitui-se necessário ainda um melhoramento na estrutura de venda da cidade. Alguns profissionais alegaram também a pouca lucratividade com o trabalho que desenvolvem, como pode ser observado na fala de um dos participantes: "Para nossa área, o mercado é melhor nos feriados e férias. A gente só vende bem nas altas temporadas" - (Participante 6).

Entretanto, a problemática da falta de campo de trabalho não é uma realidade para todos, o que motiva o exercício da profissão, como ressalta um dos entrevistados: "Tem dia que eu tenho que escolher para onde eu vou. Eu vivo bem nesses termos e trabalho muito" - (Participante7).

Desta forma, o profissional se sente satisfeito com o mercado de trabalho que a cidade oferece e mantém-se inserido na cadeia produtiva do mercado formal e no informal. Considerando os resultados acima apresentados, julgam-se necessárias algumas considerações finais sobre a pesquisa.

\section{CONSIDERAÇÕES FINAIS}

Diante dos resultados encontrados conclui-se que os modelos de carreira profissional elaborados por parte dos profissionais da área das artes na cidade de 
Parnaíba-PI são vários como, por exemplo, carreira de tipo empreendedor, âncoras de carreiras e o craft careers, além disto, são profissionais motivados a exercerem suas profissões e isso faz com que eles se empenhem a um aprimoramento contínuo por meio de cursos e tecnologias para oferecer um trabalho de qualidade.

Os resultados encontrados corroboram com a literatura acerca da gestão de carreira, no sentido que o indivíduo não permanece apenas ligado à uma organização. Novas formas de administrar a carreira vêm surgindo sendo levado em consideração a satisfação pessoal para o exercício da profissão. O campo das artes em Parnaíba apresenta-se vasto e pouco explorado, desta forma sugere-se a execução de novos estudos exploratórios acerca da temática.

\section{REFERÊNCIAS}

BALASSIANO, M.; COSTA, I. S. F. Gestão de carreiras: dilemas e perspectivas. São Paulo: Ed. Altas, 2013.

BALASSIANO, M.; VENTURA, E. C. F.; FONTES FILHO, J. R. Carreiras e cidades: existiria um melhor lugar para se fazer carreira?. RAC, v. 8, n. 3, jul./set. 2004.

BARDIN, L. Análise de conteúdo. São Paulo: Edições 70, 2011.

BENDASSOLLI, P. F. Psicologia e trabalho: apropriações e significados. São Paulo: Ed. Cengage, 2009a.

BENDASSOLLI, P. F. Recomposição da relação sujeito-trabalho nos modelos emergentes de carreira. RAE, São Paulo: v. 49, n. 4, 2009b.

BRASIL. Base conceitual do artesanato brasileiro. Brasília: Ministério do Desenvolvimento, Indústria e Comércio Exterior, 2012.

CHANLAT, J. F. Quais carreiras e para qual sociedade?. Revista de Administração de Empresas, São Paulo, v. 35, n. 6, nov./dez. 1995.

DE LUCA, G.; ROCHA-DE-OLIVEIRA, S.; CHIESA, C. D. Projeto e metamorfose: 
contribuições de Gilberto Velho para os estudos sobre carreiras. Revista de Administração Contemporânea, v. 20, n. 4, p. 458-476, jul./ago. 2016.

DIAS, C. M. M. O Piauí que o Brasil quer ver: história, arte e cultura. Teresina: EDUFPI, 2013.

DUTRA, J. S. Administração de carreiras: uma proposta para repensar a gestão de pessoas. São Paulo: Ed. Atlas, 2010.

FÉRAL, J. Além dos limites: teoria e prática do teatro. São Paulo: Ed. Perspectiva, 2015.

GOMBRICH, E. H. A história da arte. 16. ed. São Paulo: Ed. Guanabara, 2000.

JANSON, H. W.; JANSON, A. Iniciação a história da arte. 2. ed. São Paulo: Ed. Martins Fontes, 1996.

LIMA, L. R. Arte em madeira do Piauí: Santos e sertões do imaginário. Rio de Janeiro: IPHAN: CNFCP, 2010.

MASLOW, A. H. Motivation and personality. New York: Harper e Row, 1954.

MATOS, E.; PIRES, D. Teorias administrativas e organização do trabalho: de Taylor aos dias atuais, influências no setor saúde e na enfermagem. Texto Contexto Enfermagem, v. 15. n. 3, jul./set. 2006.

MENEZES, G. Praia, história e artesanato no Piauí. O Globo, 2013.

MONTEIRO, M. S. H.; LEITE, D. B. Perspectivas de carreira dos estudantes de administração da Universidade Federal de Mato Grosso: comparativo entre os estudantes das gerações X e Y. Navus-Revista de Gestão e Tecnologia, v. 9, n. 1, p. 87-104, 2019.

MORAES, J. G. V. História e música: canção popular e conhecimento histórico. Revista Brasileira de História, São Paulo, v. 2. n. 39, 2000.

MUNHOZ, I. M. S.; MELO-SILVA, L. L. Educação para a carreira: concepções, 
desenvolvimento e possibilidades no contexto brasileiro. Revista Brasileira de Orientação Profissional, v. 12, n. 1, jun. 2011.

NEVES, M. M.; TREVISAN, L. N.; JOÃO, B. do N. Carreira proteana: revisão teórica e análise bibliométrica. Revista de Psicologia Organizacional e do Trabalho, v. 13, n. 2, 2013.

OLIVEIRA, C. S. Do teatro à performance: um lugar de colapso. Revista Landa, v. 6, n. 1, p. 22-40, jun. 2017.

OLIVEIRA, M. Z. et al. Validação da versão brasileira da escala de atitudes de carreira sem-fronteiras. Arquivos Brasileiros de Psicologia, v. 62, n. 3, 2010.

ORNELLAS, T. C. F.; MONTEIRO, M. I. Aspectos históricos, culturais e sociais do trabalhador. Revista Brasileira de Enfermagem, v. 59. n. 4. jul./ago. 2006.

PEDROSA, F. B. O.; SANTOS, J. N. Da relação entre projeto de vida e o opt-out na carreira. In: ENCONTRO DE GESTÃO DE PESSOAS E RELAÇÕES DE TRABALHO, 5., 2015, Salvador. Anais [...]. Salvador: ANPAD, 2015.

PÉREZ-RAMOS, J. Motivação no trabalho: abordagens teóricas. Psicologia USP, São Paulo, v. 1, n. 2, dez. 1990.

ROCHA, M. A. et al. Arte de perto, volume único. 1. ed. São Paulo: Leya, 2016.

SCHEIN, E. H. Career anchors and job planning: the links between career pathing and career development. Cambridge: MIT Review, 1990.

SILVA FILHO, F. P. Perfil e problemática do artesanato do Litoral Piauiense. Fortaleza: Fundação Delta do Parnaíba, 1987.

TAMAYO, A.; PASCHOAL, T. A relação da motivação para o trabalho com as metas do trabalhador. Revista de Administração Contemporânea, v. 7, n. 4, out./dez. 2003.

TOLFO, S. R. A carreira profissional e seus movimentos: revendo conceitos e formas de gestão em tempos de mudança. Revista Psicologia: Organização e Trabalho, v. 2 , n. 2, 2002. 
TREVISAN, L. N. et al. Âncoras de carreira e tecnologia na percepção sobre estresse no ambiente de trabalho. Organizaçóes em Contexto, v. 12, n. 24, jul./dez. 2016.

VIEIRA, C. L. S.; SOUSA, P. A. Carreira profissional no artesanato: um estudo com artesãos escultores em madeira. RECAPE Revista de Carreiras e Pessoas, v. 9, n. $1,2019$.

WILKOSZYNSKI, C. C.; VIEIRA, F. O. Carreiras contemporâneas: desafios e contradições frente as mudanças no mundo do trabalho. Desenvolve: Revista de Gestão do UnilaSalle, v. 2, n. 1, mar. 2013.

Recebido em: 21/01/2019

Aceito em: 24/06/2019 